\title{
DISRUPTION OF THE AORTIC ARCH CONVEXITY CONTAINING THE INNOMINATE AND LEFT COMMON CAROTID ARTERY ORIGINS RESULTING FROM BLUNT TRAUMA
}

\author{
Afksendiyos Kalangos, MD, PhD, Aristotelis Panos, MD, Robert Dechamboux, MD, and Bernard Faidutti, MD, \\ Geneva, Switzerland
}

In civilian practice, blunt injuries to the aortic arch and its vessels are uncommon. ${ }^{1}$ Their diagnosis and surgical management occasionally present challenging problems. This report describes the clinical picture, angiographic findings, and surgical management of an aortic arch tear that resembled an injury to the left common carotid artery (LCCA).

A 50-year-old man sustained blunt chest trauma when he was crushed against an obstacle despite efforts to stop when skiing off-piste. He was described as hemiplegic on the right side, semicomatose, and diaphoretic by the alpine emergency physician, who intubated and transferred him rapidly to the emergency room of our institution. On his arrival, he was unconscious and had right hemiplegia. Physical examination revealed a blood pressure of $150 / 80 \mathrm{~mm} \mathrm{Hg}$, symmetric pulses, normal findings on cardiac auscultation, and no significant external injury. The chest x-ray film disclosed no rib fractures, pneumothorax, pleural effusions, pulmonary contusion, or substantial mediastinal widening. Cerebral computed tomographic (CT) scan excluded signs of closed head injury. Chest CT scan disclosed a subadventitial hematoma along the aortic arch and excluded aortic dissection (Fig. 1, $A$ ). Therefore the patient underwent aortography to avoid neglect of a possible injury to the LCCA. Arch aortography demonstrated an anterior mediastinal extravasation of contrast material from the aortic arch, which was superposed between the origins of the innominate artery and LCCA. The LCCA was stenosed at its origin, and there was another apparent image of mediastinal contrast extravasation (Fig. 1, $B$ ).

The patient was taken to the operating room immediately after these studies, 4 hours after the accident, and a median sternotomy was made. The pericardium was free of blood and the ascending aorta was apparently normal. When the innominate artery was exposed at the pericar-

From the University Cantonal Hospital of Geneva, Clinic for Cardiovascular Surgery, Geneva, Switzerland.

Received for publication August 23, 1996; accepted for publication Sept 30, 1996.

Address for reprints: Afksendiyos Kalangos, MD, $\mathrm{PhD}$, University Cantonal Hospital of Geneva, Clinic for Cardiovascular Surgery, 24, rue micheli-du-Crest, 1211 Geneva, 14, Switzerland.

J Thorac Cardiovase Surg 1997;114:129-31

Copyright (C 1997 by Mosby-Year Book, Inc.

$0022-5223 / 97 \$ 5.00+0 \quad \mathbf{1 2 / 5 4 / 7 8 3 8 2}$ dial reflection, a large subadventitial hematoma of the aortic arch was observed. The incision was extended up to the right side of the neck along the anterior border of the sternomastoid muscle and then the right common carotid artery and LCCA were dissected free for control. The patient was supported by cardiopulmonary bypass with inflow into the right femoral artery and venous return to the pump from a long cannula placed in the right atrium through the right femoral vein. The carotid arteries were then cannulated, crossclamped, and perfused with blood cooled to $6^{\circ}$ to $10^{\circ} \mathrm{C}$ through a separate heat exchanger when rectal temperature reached $30^{\circ} \mathrm{C}$. $^{2}$ The ascending aorta was crossclamped and myocardial protection was obtained by cold blood potassium cardioplegia. Cardiopulmonary bypass was then discontinued when rectal temperature reached $25^{\circ} \mathrm{C}$. The distal half of the ascending aorta was opened longitudinally, and through it the origins of the aortic arch vessels were inspected. A circumferential intimal and medial disruption of the aortic arch, running $1 \mathrm{~cm}$ from the origins of the innominate artery and LCCA, was hence revealed (Fig. 2). The hematoma was contained within the adventitia and periadventitial tissues of the aortic arch, thereby preventing hemorrhage. Stenosis of the LCCA, visualized by arteriography, was due to the compressive effect of a posterior subadventitial hematoma extended up to $3 \mathrm{~cm}$ distal to the takeoff of the LCCA from the aortic arch. No intimal disruption was detected in the innominate artery and the LCCA. The aortotomy was extended up to the left subclavian artery (LSCA) and the aortic arch was resected because of the tear between the LCCA and LSCA, leaving the latter artery attached to the distal aortic arch. A 28 $\mathrm{mm}$ preclotted woven Dacron prosthesis was then interposed between the distal aortic arch stump and the proximal ascending aorta. After deairing, the ascending aorta was unclamped and core rewarming started. A bifurcation graft size $20 / 10 \mathrm{~mm}$ was inserted from the aortic arch prosthesis to the innominate artery and the LCCA. The body of the bypass graft was cut close to its bifurcation, and a proximal anastomosis was performed with partial clamping of the aortic arch prosthesis. The carotid cannulas were removed after any air bubbles had been carefully evacuated from the bypass prosthesis. Microscopically, multiple sections of the aortic arch wall specimen showed no preexisting medial degenerative changes.

The patient remained hemiplegic on awakening from anesthesia but became progressively more sensitive to stimulus over the next 2 weeks and progressed satisfacto- 

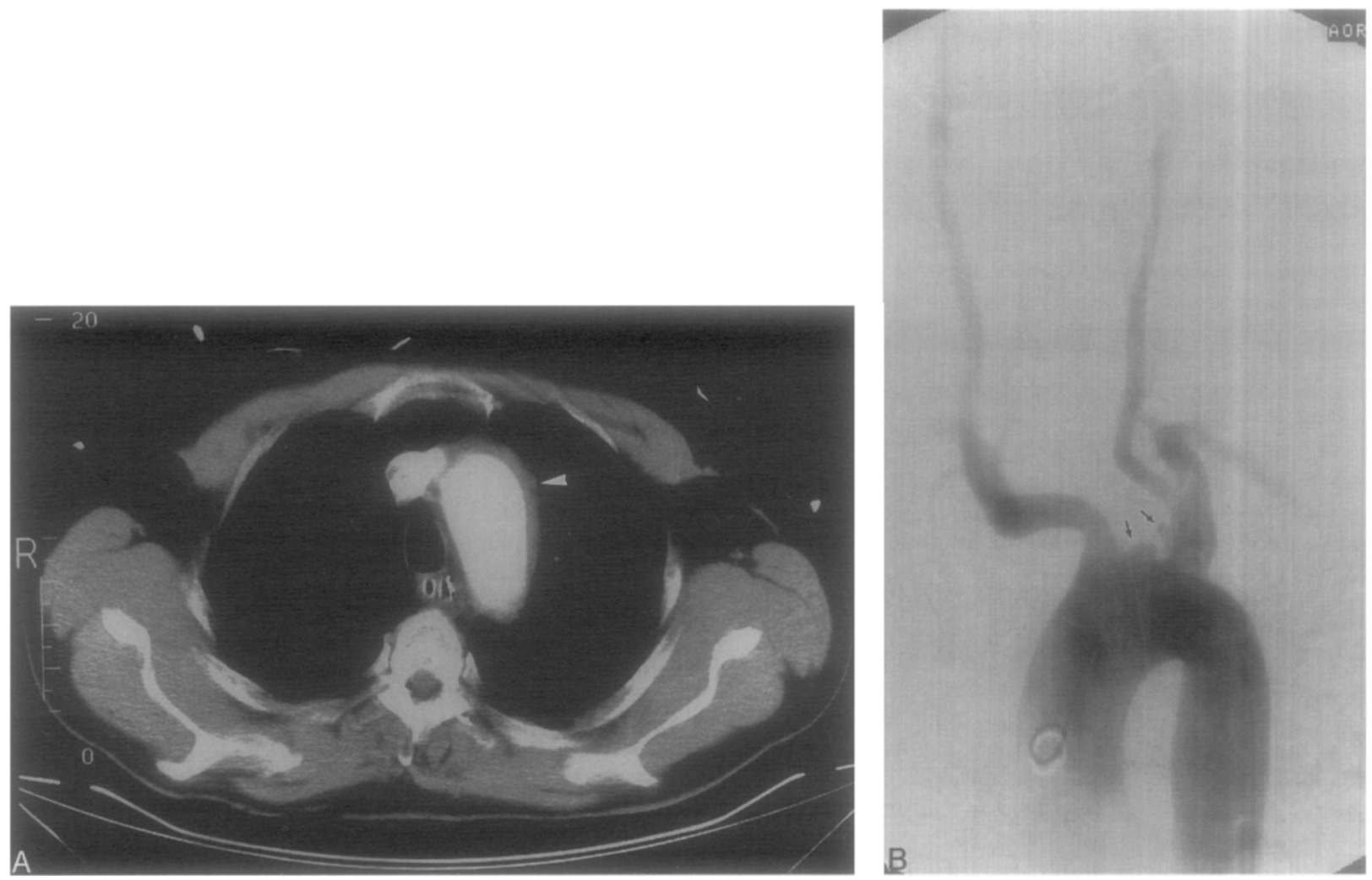

Fig. 1. Thoracic CT scan (A) showing complete subadventitial hematoma of the aortic arch (arrowhead). B, Aortogram demonstrating mediastinal extravasation of the contrast material from the aortic arch and the LCCA (arrows).

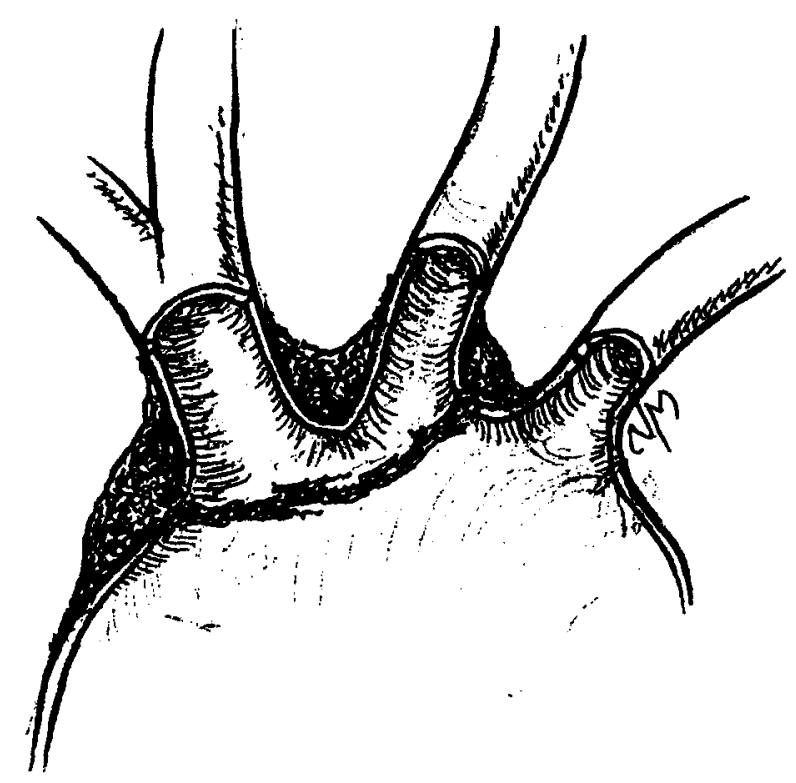

Fig. 2. Circumferential intimal disruption of the aortic arch around the origins of the innominate artery and LCCA. rily with rehabilitation therapy. $\mathrm{He}$ is ambulatory at present, 9 months after the operation, with a persistent partial Broca-type aphasia. The motor function of the right side of the body was markedly improved, although a large infarction of the left parietal and temporal cortical lobes was detected by cerebral CT scan 2 weeks after the operation.

Aortic arch injuries represent $8 \%$ of blunt injuries to the aorta. ${ }^{3}$ Although the mechanisms responsible for blunt aortic arch and great vessels injuries are not well defined, we speculate that in our case the maximal shearing and torsion stresses produced by vertical deceleration, distraction, and hyperextension of the shoulder joints during stopping efforts, as well as the association of the force of impact imposed by the sudden increase of arterial blood pressure on the aorta, might have resulted in a circumferential tear of the aortic arch near the origins of the first two great vessels. Exsanguinating hemorrhage from blunt aortic trauma is the most frequent cause of clinical presentation and death. In contrast, signs and symptoms of arterial occlusion are more frequent than massive hemorrhage in blunt trauma to the aortic arch vessels. ${ }^{1}$

Of particular interest is our patient, who had signs of injury to the LCCA rather than to the aortic arch. Controversy continues to exist regarding the best method 
of establishing a diagnosis of aortic arch vessel injury when bleeding, expanding hematoma, absent pulses, and shock are not obvious. Arteriography is not entirely reliable, the false negative rate being approximately $10 \%{ }^{4}$ In our case, the only sign leading to suspicion of an aortic arch tear was the small mediastinal extravasation of the contrast material, the outline of the aortic arch and great vessels being preserved in the other areas.

Patients with aortic or great vessel tears must be treated on an urgent basis because their condition can deteriorate at any time. The literature seems to be about equally divided between those who believe strongly that the repair of cerebral vessels in the presence of a neurologic deficit is associated with a higher risk of mortality and those who do not. Our case, however, confirmed that an obvious neurologic deficit was not worsened by carotid reconstruction and neurologic recovery may even be possible. ${ }^{5} \mathrm{We}$ believe that cannulation of carotid arteries provides a margin of safety in patients who have acute neurologic deficit attributable to cerebral ischemia after trauma. In conclusion, severe neurologic injury after blunt trauma may be due to the aortic arch tears near the origins of the innominate artery and the LCCA. Aortography should be used more liberally in patients in whom the neurologic deficit could overshadow the vascular trauma and then delay diagnosis. With the slightest suspicion, mediastinal exploration is recommended because it will allow recognition and surgical management of occult injuries. Carotid revascularization should be attempted because the neurologic impairment may be progressively reversible.

We gratefully acknowledge the technical assistance of Michel Beux.

\section{REFERENCES}

1. Rosenberg JM, Bredenberg CE, Marvasti MA, Bucknam C, Conti C, Parker FB. Blunt injuries to the aortic arch vessels. Ann Thorac Surg 1989;48:508-13.

2. Bachet J, Guilmet D, Goudot B, et al. Cold cerebroplegia: a new technique of cerebral protection during operations on the transverse aortic arch. J Thorac Cardiovasc Surg 1991;102:8594.

3. Vasko JS, Raess DH, Williams TE Jr, et al. Nonpenetrating trauma to the thoracic aorta. Surgery 1977;82:400-6.

4. Johnston RH Jr, Matthew JW Jr, Mattox KL. Innominate artery trauma: a thirty year experience. J Vasc Surg 1993;17: 134-40.

5. Robbs JV, Baker LW, Human RR, Vawda IS, Duncan H, Rajaruthnam P. Cervicomediastinal arterial injuries. Arch Surg 1981;116:663-8.

\title{
AORTIC VALVE REPLACEMENT IN RELAPSING POLYCHONDRITIS
}

\author{
Loïc Lang-Lazdunski, MD, Yves Pansard, MD, and Ulrik Hvass, MD, Paris, France
}

Relapsing polychondritis is a rare inflammatory multiorgan disorder affecting cartillaginous structures and other connective tissues. More than 600 cases have been reported to date in the literature. Serious cardiovascular complications appear in about $25 \%$ of patients with relapsing polychondritis, the most frequent being aortic or mitral regurgitation $(11.1 \%)$ and aortic aneurysms $(6.1 \%)$. We report the first Bentall-type operation in a patient with relapsing polychondritis and review the literature to point out the factors that influenced morbidity and mortality of patients requiring aortic valve replacement to

From the Department of Thoracic and Cardiovascular Surgery, Hopital Bichat, Paris, France.

Received for publication Oct. 21, 1996; accepted for publication Nov. 4, 1996.

Address for reprints: Loïc Lang-Lazdunski, MD, Service de Chirurgie Thoracique et Cardiovasculaire, Hopital Bichat, 46 rue Henri Huchard, 75877 Paris cedex 18, France.

J Thorac Cardiovasc Surg 1997;114:131-2

Copyright (C) 1997 by Mosby-Year Book, Inc.

$0022-5223 / 97 \$ 5.00+0 \quad \mathbf{1 2 / 5 4 / 7 9 1 8 0}$ determine the ideal surgical procedure for patients with relapsing polychondritis.

Case report. A 39-year-old man with relapsing polychondritis (RP) for 4 years and requiring permanent corticoid and immunosuppressive therapy for severe bilateral scleritis was admitted to our institution for recent shortness of breath. Severe aortic regurgitation associated with moderate aneurysmal dilatation of the ascending aorta (46 $\mathrm{mm}$ in diameter) were diagnosed, and the patient was referred to our department for surgical correction.

He underwent operation on February 24, 1995. The surgical procedure consisted of a Bentall-type operation with a No. 25 mechanical valvular prosthesis, with the coronary arteries being reimplanted with the use of the button technique. The postoperative course was uneventful, and the patient was discharged home on day 30 . Histologic examination of the aortic root showed acute panaortitis lesions: the intima was thickened, and the media showed extensive loss and fragmentation of elastic fibers. There were also perivascular mononuclear cell infiltrates in the outer media and in the adventitia. The aortic valve was thickened and contained inflammatory mononuclear cell infiltrates. 